\title{
VASCONCELLOS, Aulo Sanford de. Chica Pelega - a guerreira de Taquarucu. Florianópolis: Editora Insular, 2008. 200 p.
}

\author{
Marcus Roberto de Oliveira ${ }^{1}$
}

- Enviado em 01.10 .2016

- Aprovado em 03.12.2016

Quando chamamos atenção para a Guerra do Contestado (1912-1916) é fundamental compreendermos que esse evento foi materializado nos desequilibrados confrontos entre forças repressivas (civis e militares), recrutadas pelos governos na Primeira República, e milhares de sertanejos domiciliados na região que englobava a fronteira sul do Estado do Paraná e as fronteiras norte e oeste do Estado de Santa Catarina².

Neste formato, a Guerra do Contestado foi um dos motins sociais mais cruentos e ferais que já se sucederam no Brasil ${ }^{3}$. A repressão imposta, além da manutenção da "ordem" republicana, também estava alinhada aos interesses econômicos da empresa estadunidense Brazil Railway Company, pertencente ao empresário Percival Farqhuar", que no "apagar das

\footnotetext{
1 Doutorando em Sociologia pela Universidade Federal do Paraná (UFPR) e pesquisador do Núcleo de Estudos Paranaenses (NEP). Endereço eletrônico: mr_olivei@yahoo.com.br

2 "O nome deste movimento social e do posterior conflito que ali ocorreu está ligado à região em que aconteceram os fatos, ou seja, um território de disputas entre Paraná e Santa Catarina. (...) as causas da Guerra do Contestado não estão principalmente na desavença entre os governos destes estados do sul, mas sim em questões sociais e econômicas que envolveram as populações pobres de toda aquela região" (PODLASEK, 2015, p. 4).

${ }^{3}$ Um arrolamento muito interessante de dados estatísticos sobre o genocídio ocorrido na Guerra do Contestado está disponível em http://www.histedbr.fe.unicamp.br/revista/revis/revis16/img4 16.pdf; acesso em $07 / 09 / 2016$.

4 "Percival Farquhar nasceu em York, na Pensilvânia, EUA, em 19 de outubro de 1864, filho de Arthur Briggs Farquhar, um bem-sucedido industrial norte-americano. Cursou o York Collegiate Institute, ingressando mais tarde na Universidade de Yale, pela qual se formou em engenharia em 1884". Disponível em 
luzes" do Império, assumiu a construção de uma grande ferrovia (que buscava integrar economicamente as regiões sul e sudeste) e a exploração "das terras marginais para $15 \mathrm{~km}$ de cada lado do eixo da rodovia" (VASCONCELLOS, 2008, p. 23). No seu avanço, para "a exploração da madeira ao longo da linha", a Railway "criou a Southern Brazil Lumber Company, como sua subsidiária" (Idem, p. 24).

Ao longo das atividades do consórcio Railway / Lumber foram iniciados despejos no intuito de contemplar as assertivas do Decreto 305 de 7 de abril de $1890^{5}$. Nesse contexto, milhares de pessoas, entre "posseiros expulsos de suas terras, ervateiros impossibilitados de continuar os seus trabalhos" e "trabalhadores desempregados pela estrada de ferro" (CARVALHO, 2009, p. 16) uniram-se em torno da liderança messiânica ${ }^{6}$ do monge José Maria ${ }^{7}$. Tais agentes sociais (BOURDIEU, 1996) passaram a aderir ao movimento que teve como evento baliza o "combate do Banhado Grande do Irani, ocorrido na manhã do dia 22 de outubro de 1912" (MACHAD0, 2012, p. 1).

Noutra esfera, os rebeldes também passaram a contar com o apoio de "antigas lideranças federalistas ${ }^{8}$ e importantes políticos opositores dos coronéis da região"

http://cpdoc.fgv.br/sites/default/files/verbetes/primeira-republica/FARQUHAR,\%20Percival.pdf; acesso em $01 / 09 / 2016$

5 Ver $\quad$ http://www2.camara.leg.br/legin/fed/decret/1824-1899/decreto-305-7-abril-1890-523631publicacaooriginal-1-pe.html; acesso em 01/09/2016.

${ }^{6}$ Trata-se de um líder carismático (beato, monge, etc.) que não era ligado à Igreja, nem tinha sua aprovação. Tais lideranças inspiravam os movimentos messiânicos: "simples contestações pacíficas quanto a aspectos selecionados da vida social" ou "rebeldias armadas, ambos os tipos informados pelo universo ideológico religioso" (NEGRÃO, 2001, p. 119).

7 “(...) em 1912. Miguel Lucena de Boaventura, um curador de ervas, autodenominado José Maria de Santo Agostinho, atraiu centenas de pessoas, que permaneceram ao seu redor na localidade conhecida como Taquaruçu. Lá ele abriu uma espécie de consultório, chamado 'Farmácia do Povo', utilizando as diferentes ervas da região e elaborando receitas, como esta citada pelo jornal Diário da Tarde em 1912: 'entravam sassafraz, raiz de xaxim e outras raízes, na proporção de 700 gramas em uma garrafa de cachaça, para os doentes ingerirem em grandes doses'". Disponível em http://www.revistadehistoria.com.br/secao/capa/monges-peregrinos; acesso em 02/09/2016.

8 "Muito sangue foi derramado para que a República pudesse se sustentar nos anos que se seguiram à sua Proclamação. No Rio Grande do Sul houve até degolas. O fato é que havia muitos interesses em jogo durante os governos militares de Deodoro da Fonseca (1827-1892) e Floriano Peixoto (1839-1895). Os dois presidentes precisaram conciliar os negócios da economia cafeeira com a manutenção da unidade nacional. Mas não o fizeram sem resistência. (...) Um dos movimentos que mais contestaram a soberania dos republicanos foi a 
(CARVALHO, 2009, p. 17). Toda essa situação trouxe preocupação para a elite dominante local e o governo federal na época, pois os acontecimentos referentes a Canudos (1893-1897) ${ }^{9}$ ainda eram recentes.

Vários conflitos se espalharam pela região, diversos prejuízos (de ordem cultural, econômica, política e social) foram acarretados e o levante trouxe à tona uma face que o "moderno" e "europeizado" sul brasileiro buscou (e ainda busca) esconder ${ }^{10}$. Nesse sentido, é plausível sustentar que o escritor catarinense Aulo Sanford de Vasconcellos denuncia poeticamente tal exclusão na obra "Chica Pelega - A Guerreira do Taquaruçu" (VASCONCELLOS, 2008).

No texto, o personagem Pedro da Silva, um jornalista inquieto na sua aposentadoria e resistente a cuidar do jardim de sua casa por inaptidão confessa, revela seu deslumbramento pelo tema da Guerra do Contestado; assunto esse que tomou conhecimento a partir de uma pesquisa do historiador Oswaldo Rodrigues Cabral11. Por meio de um romance histórico, decide narrar, em primeira pessoa, a saga de Francisca Roberta, a Chica Pelega, a legendária heroína da insurreição ${ }^{12}$.

Chica Pelega possuía uma "habilidade natural" para lidar com animais, enfermidades e todos os afazeres do cotidiano rural na época. Perdeu o pai Zinho, o tio Charrua e o namorado Zico em uma chacina efetivada pela Brazil Railway numa ação de despejo, e com sua mãe

Revolução Federalista, uma série de conflitos armados que ocorreram nos três estados do Sul do Brasil entre 1893 e 1895". Disponível em http://www.revistadehistoria.com.br/secao/artigos/prova-de-fogo-republicana; acesso em 03/09/2016.

90 "Arraial do Belo Monte", também conhecido por Canudos, foi fundado pelo líder messiânico Antônio Conselheiro e localizava-se no interior da Bahia. "A presença de milhares de sertanejos, vivendo em uma comunidade que não aceitava muitas das regras da República e do coronelismo, se constituía não só em um desafio ao poder dos coronéis, mas também em um perigo real de rebeldia em massa contra a ordem vigente na época". O vilarejo foi arrasado pelo exército republicano brasileiro em 1897 (PODLASEK, 2015, p. 2-3).

10 Sobre tais questões ver http://www.histedbr.fe.unicamp.br/revista/revis/revis16/img4 16.pdf; acesso em 07/09/2016 e https://www.youtube.com/watch?v=vzOCG6i4i44; acesso em 01/09/2016.

11 Disponível em http://www1.an.com.br/ancapital/2001/mar/18/1ult.htm; acesso em 03/09/2016.

12 "Chica Pelega é pouco citada nos livros e para muitos nem existiu". Sua comparência está assentada em “(...) depoimentos de testemunhas oculares. Na memória de muitos sertanejos é uma heroína dos sertões, dividindo espaços com a também admirada virgem Maria Rosa, de quem há muitas recordações". Disponível em http://www.diarioriodopeixe.com/cultura/7481-ha-100-anos-chica-pelega-era-morta-por-militares/; acesso em 31/08/2016. 
Chiquinha, juntaram-se aos romeiros seguidores do monge José Maria em Taquaruçu (região que hoje pertence ao município de Fraiburgo - SC).

Ao longo das duzentas páginas do livro, Vasconcellos destaca o protagonismo feminino na Guerra do Contestado a partir da figura de Chica Pelega. 0 autor sublinha sua dedicação em cuidar dos doentes e feridos, bem como sua destreza na montaria e no manejo do facão, lançando mão de uma articulada redação que combina harmonicamente significativos detalhes num contexto que conjuga devoção religiosa, difusão política e plena exclusão social. No ano de 2014, sua percepção foi reforçada pela imprensa catarinense:

(...) o casamento desastrosamente não aconteceu, porque Zico, toda a família e o pai de Chica, além de centenas de colonos, foram mortos por jagunços. Chica e a mãe, que estavam trabalhando na nova terra, sobreviveram, enterraram os mortos e, junto com sua dor, embrenharam-se no mato, onde foram encontrando outros escorraçados. Apoiando-se uns aos outros, formaram um grupo errante com ex-trabalhadores da estrada de ferro, que por aceitação natural Chica Pelega liderava. Alimentavam-se de raízes, corós e larvas. (...) Ouviram falar do monge José Maria, o curandeiro ressuscitado, que estava indo para Taquaruçu, nos limites de Curitibanos, onde aconteceria a "festa do Senhor Bom Jesus". Então, o grupo seguiu para lá e passou a viver sob a liderança do monge. (...) Chica Pelega assumiu papel de destaque, admirada por todos. Ela passava a maior parte do tempo em uma enfermaria improvisada, logo ganhando a simpatia e gratidão de todos. Por isso, ganhou de presente um cavalo e uma espécie de mantilha de lã, forrada, felpuda como um pelego, que atava ao pescoço. Ficou conhecida como a "Chica" que montava melhor que homem, com seu "Pelego" ao vento... E passou a ser carinhosamente chamada de "Chica Pelega"13.

0 desfecho da história de Chica Pelega foi trágico. Em 8 de fevereiro de 1914 o acampamento de Taquaruçu foi completamente arrasado pelas forças militares governistas ${ }^{14}$. A heroína morreu nesse dia nos braços de sua mãe Chiquinha, cuidando dos enfermos e lutando ao lado dos sertanejos:

Um pouco antes do cessar-fogo, quando inda haviam bombas estourando e cerrados estampidos sacudindo a noite, ouviu-se, com terna sonoridade, uma canção de ninar.

13 Disponível em http://www.diarioriodopeixe.com/cultura/7481-ha-100-anos-chica-pelega-era-morta-pormilitares/; acesso em 31/08/2016.

${ }^{14}$ Disponível em http://www.histedbr.fe.unicamp.br/revista/revis/revis16/img4 16.pdf; acesso em 07/09/2016. 
Uma voz de embalo morno e suave a contrastar com os ásperos ribombos da violenta razia. E então se viu, no relance de um clarão, a mãe de Chica Pelega sentada na lama com a ensanguentada cabeça da filha no colo. Alisava-lhe a cabeça e cantava com doçura, indiferente aos estouros dos obuses, a sua velha canção de ninar. (...) Enlouquecera, em piedosa loucura, agarrada ao cadáver da filha (VASCONCELLOS, 2008, p. 194-195).

Vasconcellos finaliza sua obra ressaltando a imortalidade de Chica Pelega enquanto um ícone do campesinato sulista da época, sinalizando estender tal compreensão até os dias de hoje. Conforme o autor, a protagonista "eram todos. E não se matam todos, que são impessoais. Por isso ela não morreu. Ei-la, algures, a trágica Chica Pelega, a filha da terra, irmã do rio, basta olhar e querer vê-la" (Idem, p. 196).

0 atributo coletivo do termo "todos" revela o anonimato dos integrantes do Contestado. Nesse ponto, com base no livro, a árvore genealógica de Chica Pelega (ou Francisca Roberta) é um exemplo significativo, com os pais Chiquinha e Zinho e seus avós e bisavós anônimos.

A ausência dos nomes e/ou sobrenomes, juntamente com um intencional e desonesto estigma caracterizaram os dizimados do episódio nos mais variados tipos de relatos. De acordo com o historiador Paulo Pinheiro Machado:

Por muito tempo o estudo sobre o conflito do Contestado refletiu todos os preconceitos que existem sobre as populações rurais em geral e, em especial, os caboclos. "Matutos", "tabaréus" e outras denominações pejorativas aos habitantes nacionais indicavam uma mistura de preconceito racial (contra negros, indígenas e mestiços) associado ao preconceito urbano e de classe, contra os camponeses em geral. Esta população - desde as primeiras crônicas na imprensa, nos relatórios de militares, médicos e de autoridades políticas - era tratada como um povo ignorante, desprovido de civilidade, despreparado para qualquer política de modernização, preso às superstições e guiado por charlatães e exploradores de sua fé ingênua. 0 problema é que estas visões preconceituosas, que acabaram por considerar os seguidores de José Maria como "fanáticos", não ficaram restritas às fontes. Foi reproduzida pela literatura científica sobre o tema. Não foram poucos os historiadores a amplificar as expressões de "fanatismo" e "aberração". Os sertanejos eram vistos por suas carências e pelo que não eram (MACHADO, 2012, p. 1). 
Portanto, mesmo com uma evidente precariedade de fontes, há um significativo campo aberto para estudos biográficos acerca de uma diversidade de agentes sociais que compuseram o movimento do Contestado. No Brasil, essas pessoas foram injustamente relegadas ao vácuo da história por décadas (em muitos momentos ainda o são), e heroicamente deixaram a "ordem" e o "progresso" constrangidos por praticamente todo século XX.

\section{REFERÊNCIAS}

\section{Referências bibliográficas}

BOURDIEU, P. (1996). Razões práticas: sobre a teoria da ação. Campinas: Papirus.

CARVAlHO, T. M. (2009). Coerção e consenso na Primeira República: a guerra do Contestado (1912-1916). Tese (Doutorado em História), Instituto de Ciências Humanas e Filosofia, Universidade Federal Fluminense.

MACHADO, P. P. (2012). O Centenário do movimento do Contestado (1912/2012) - história, memória e historiografia. [s/l]: [s/ed].

NEGRÃO, L. N. (2001). "Revisitando o messianismo no Brasil e profetizando seu futuro". Revista Brasileira de Ciências Sociais, vol.16, n.46, pp.119-129.

PODLASEK, L. (2015). Movimentos sociais rurais na Primeira República. Curitiba: [s/ed]. VASCONCELLOS, A. S. (2008). Chica Pelega - a guerreira de Taquaruçu. Florianópolis: Insular.

\section{Referências digitais}

"A guerra do Contestado". Disponível em http://www.histedbr.fe.unicamp.br/revista/revis/revis16/img4 16.pdf; acesso em 07/09/2016.

“Contestado: Uma Guerra Esquecida - Caminhos da Reportagem”. Disponível em https://www.youtube.com/watch?v=vzOCG6i4i44; acesso em 01/09/2016.

“Decreto no 305, de 7 de Abril de 1890”. Disponível em http://www2.camara.leg.br/legin/fed/decret/1824-1899/decreto-305-7-abril-1890523631-publicacaooriginal-1-pe.html; acesso em 01/09/2016. 
"FARQUHAR, PERCIVAL". Disponível em http://cpdoc.fgv.br/sites/default/files/verbetes/primeirarepublica/FARQUHAR,\%20Percival.pdf; acesso em 01/09/2016.

"Há 100 anos Chica Pelega era morta por militares". Disponível em http://www.diarioriodopeixe.com/cultura/7481-ha-100-anos-chica-pelega-era-morta-pormilitares/; acesso em 31/08/2016.

"Monges peregrinos" - Disponível em http://www.revistadehistoria.com.br/secao/capa/monges-peregrinos; acesso em 02/09/2016.

"Oswaldo Cabral - um catarinense que fez história" - Disponível em http://www1.an.com.br/ancapital/2001/mar/18/1ult.htm; acesso em 03/09/2016.

"Prova de fogo republicana" - Disponível em http://www.revistadehistoria.com.br/secao/artigos/prova-de-fogo-republicana; acesso em 03/09/2016. 